\title{
Long-delayed report on Bhopal disaster offers little new information
}

Indian scientists have released a report on the gas leak in Bhopal, a decade after the studies ended, and nearly 20 years after the disaster.

On 3 December 1984, 40 tons of methyl isocyanate leaking from a Union Carbide pesticide plant killed more than 3,000 people and ๖ left hundreds of thousands with chronic lung, eye and gynecological problems.

The Indian Council of Medical Research (ICMR) initiated 24 research projects, including long-term epidemiological, toxic and clinical studies on 80,000 persons from severely, moderately and mildly exposed areas and control unexposed areas. But it abruptly terminated the studies in 1994, without any explanation.

As a result of a legal battle with Union Carbide, the Indian government also blocked release of the studies in scientific journals and elsewhere.

The ICMR finally released the results in November 2004, by which time four members of the research team have passed away. "The results are possibly outdated," says Samavedam Sriramachari, scientist emeritus at ICMR and one of the investigators.

"[The long delay] violates the objectives of the exercise as well as the ethics of research," says Satinath Sarangi, a spokesperson for Sambhavna Trust, a Bhopal-based nongovernmental organization that assists survivors.

The ICMR report says most deaths were due

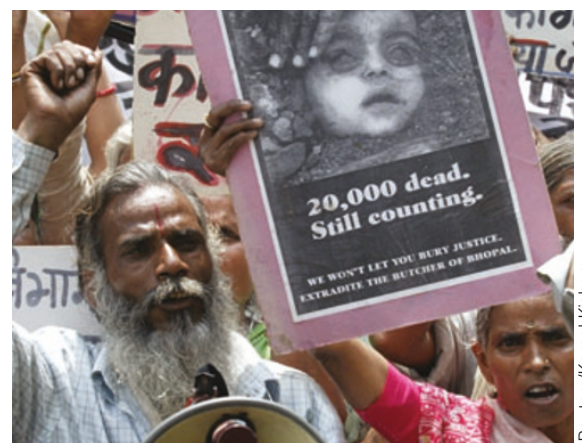

Bhopal's water is still contaminated 20 years on.

to asphyxia resulting from acute lung injury, chemical pneumonia and acute respiratory distress syndrome caused by cyanide poisoning. The affected areas had a persistent high death rate between 1984 and 1993, primarily from respiratory disorders, and high rates of respiratory, ophthalmic and gastrointestinal disorders.

Ingrid Eckerman, a public health expert from Sweden, says the study design is flawed, and research is rudimentary or missing in some fields. Eckerman and 12 other researchers from international agencies served on the International Medical Commission on Bhopal, which in 1994 conducted an independent survey on the health, economic and social consequences of the disaster. Eckerman also notes that little research has been done on female reproduction, or on chromosomal aberrations, post-traumatic stress disorder or the health of children born after the disaster.

The ICMR report calls for more follow-up studies, especially on possible cancers-but in the past 20 years, many members of the original cohort have died or migrated. "We have done the maximum possible studies," says Sriramachari.

Venkata Ramana Dhara, an occupational and environmental health researcher at Emory University in Atlanta, has proposed a simulation of the disaster at a US Department of Energy test site in the Nevada desert to study the gas cloud and how it spread into the environment. But such a test is "unlikely to yield any information applicable to the survivors," notes Sriramachari.

Meanwhile, toxic wastes are still lying at the pesticide plant-now owned by Dow Chemicals_contaminating groundwater in nearby areas. Organizations such as Greenpeace, Sambhavna and a recent BBC team have highlighted the adverse health effects resulting from the contamination.

"It is high time the government and other agencies undertook the responsibility of clearing the wastes, instead of getting caught in legal wrangles over who should pay for the removal," says Sriramachari.

T. V.Padma, New Delhi

\section{New York City foster home accused of unethical AIDS drug trials}

Just months after a Kenyan orphanage was accused of conducting unauthorized drug

trials on HIV-positive orphans, similar charges have surfaced in the US. Federal agencies are investigating allegations of misconduct in AIDS drug trials using children in New York City foster care.

In December, a BBC report aired interviews with children claiming that when new treatments made them sick, they were forcefed the drugs. The report also showed foster parents who said their children were taken away when they stopped giving them the drugs.

The charges focus on the Incarnation Children's Center (ICC) in Manhattan. From the early 1990s through 2002, about 60 HIV-positive children at the center took part in dozens of national clinical trials run by researchers at Columbia University Medical Center and other area hospitals.

The ICC denies the allegations. "Of course some kids were reluctant, as kids are, to take their medicine," says Gerald McKelvey, a spokesperson for the ICC. But children were never force-fed, McKelvey says.
The trials were approved by the Pediatric AIDS Clinical Trials Group (PACTG), a self-governing network that sets standards for care of HIV-infected children and is supported by the US National Institutes of Health. Some trials were sponsored by drug companies, including Genentech, Bristol-Myers Squibb and GlaxoSmithKline.

The accusations were first published by Liam Scheff, a freelance journalist who does not believe that HIV causes AIDS. In his report, Scheff wrote, “If we don't know how HIV works, or if it makes anyone sick, then it's unethical to treat any HIV-positive person with potentially fatal pharmaceuticals."

In rare cases, the city took children away from foster parents who refused to give them the drugs, says McKelvey. According to a written statement from Columbia University, the drugs' side effects were never serious enough to warrant discontinuing treatment.

Most researchers agree that pediatric drugs should be tested in children because children react to diseases and drugs differently than adults do. Under federal law, parents have the right to decide how to balance the promise of new treatments with any adverse affects, and can pull a child out of a trial at any time.

But for foster children, whose legal guardian is a city or state agency, informed consent is more complicated. In the early 1990s, New York City's Department of Health had the power to enroll these children in drug trials. That power now belongs to the city's Administration for Children's Services.

One patient advocacy group, the Alliance for Human Research Protection, says the city has violated federal regulations by not requiring separate consent for each child. The group is calling for a moratorium on using foster children in phase 1 and 2 trials.

"That would be a major mistake," says Ram Yogev, who chairs the PACTG's Primary Therapy Research Agenda Committee. "[Foster] kids should have the same right to get the newest drugs as they are available," he says. "Otherwise you deny these kids drugs that might elongate their lives."

Jascha Hoffman, New York 